\title{
THE EVALUATION OF PREFERENCES OF CONSUMERS FOR COFFEE SHOP CHAINS IN TURKEY
}

\begin{abstract}
This study aims to evaluate the preferences of consumers for coffee shop chains in Turkey with respect to the social, economic, and brand equity aspects. The research provides a tool to determine factors affecting coffee shop chain preferences, to prioritize these factors, and also to find the most preferred coffee shop chain by Turkish university students. Based on the literature review, the main criteria are identified as social dimension, environmental aspect, and brand equity. The problem on hand can be treated with AHP. The finding of the study reveals the most preferred coffee shop chain as Starbucks and the most important criterion as environmental aspect.
\end{abstract}

Keywords: coffee shop chains, consumer preference, AHP

\section{Introduction}

Coffee cultivation and trade began on the Arabian Peninsula and spread in Persia, Egypt, Syria, and Turkey by the 16th century. In addition, European people travelled to Near East and coffee reached Europe as a popular drinking. Turkish people met coffee in 1555. They discovered a new method of drinking coffee: the beans were roasted over a fire and then slowly cooked with water on the ashes of a charcoal fire. Accordingly, Turkish coffee became popular and regarded as a vital part of Turkish cuisine.

Today, coffee is a new market for both national and international brands. Accordingly, coffee shop chains are so popular with the globalized world. Over the last 20 years, our habits and diet have changed dramatically due to fast life and modernized world. Different types of coffee, e.g. instant coffee, have entered in Turkish daily life. Afterwards, international big coffee shop chains entered into the market: Gloria Jeans in 1999, Starbucks in 2003, Tchibo in 2006, and Café Nero in 2007. In the meantime, a local brand, Kahve Dunyasi, entered into the market in 2004. Nowadays there are many local and global coffee shop chains at the market. They have different marketing strategies: take-out existence; traditional tasting; offering beverages, snacks, and desserts; using renewable materials and energy. To gain competitive advantage, coffee shop chains should understand the preferences of consumers as well. Evaluation of preferences necessitates a multi criteria decision making (MCDM) approach. In this study, the problem on hand will be treated with AHP, one of the most widely used MCDM method.

\section{Decision Model}

Over last 20 years, the habits, the priorities, and the diet of consumers have changed dramatically because of the modern life. Accordingly, these changes affected the preferences of consumers at food and beverage industry. Understanding the economic and social factors as well as brand related issues related with these effects will sustain a competitive advantage for the brands in the industry. Evaluating consumer preferences necessitates a multi criteria decision making approach as there are several, conflicting, weighted, and incommensurable criteria.

In this study, the evaluation of preferences of consumers for coffee shop chains in Turkey are taken into consideration. As the decision model can be represented as a hierarchy, to 
analyze it, Analytic Hierarchy Process, one of the most widely used multi-criteria decision method, is utilized.

Based on literature review (Bhumiratana et al., 2014; Han et al., 2015; Jeong et al., 2014;; Nam et al., 2011; Tumanan and Lansangan, 2012; Vanharanta et al., 2015) and judgment of experts (managers of coffee shop chains), the main evaluation criteria are identified as brand equity, environmental aspects, and social dimension. Additionally, the sub-criteria are identified as follows: physical quality, staff behavior, and brand loyalty for brand equity; materials and green practices for environmental aspect; and meeting people and activities for social dimension. The revealed decision model is represented as a hierarchy as can be seen at Figure 1 .

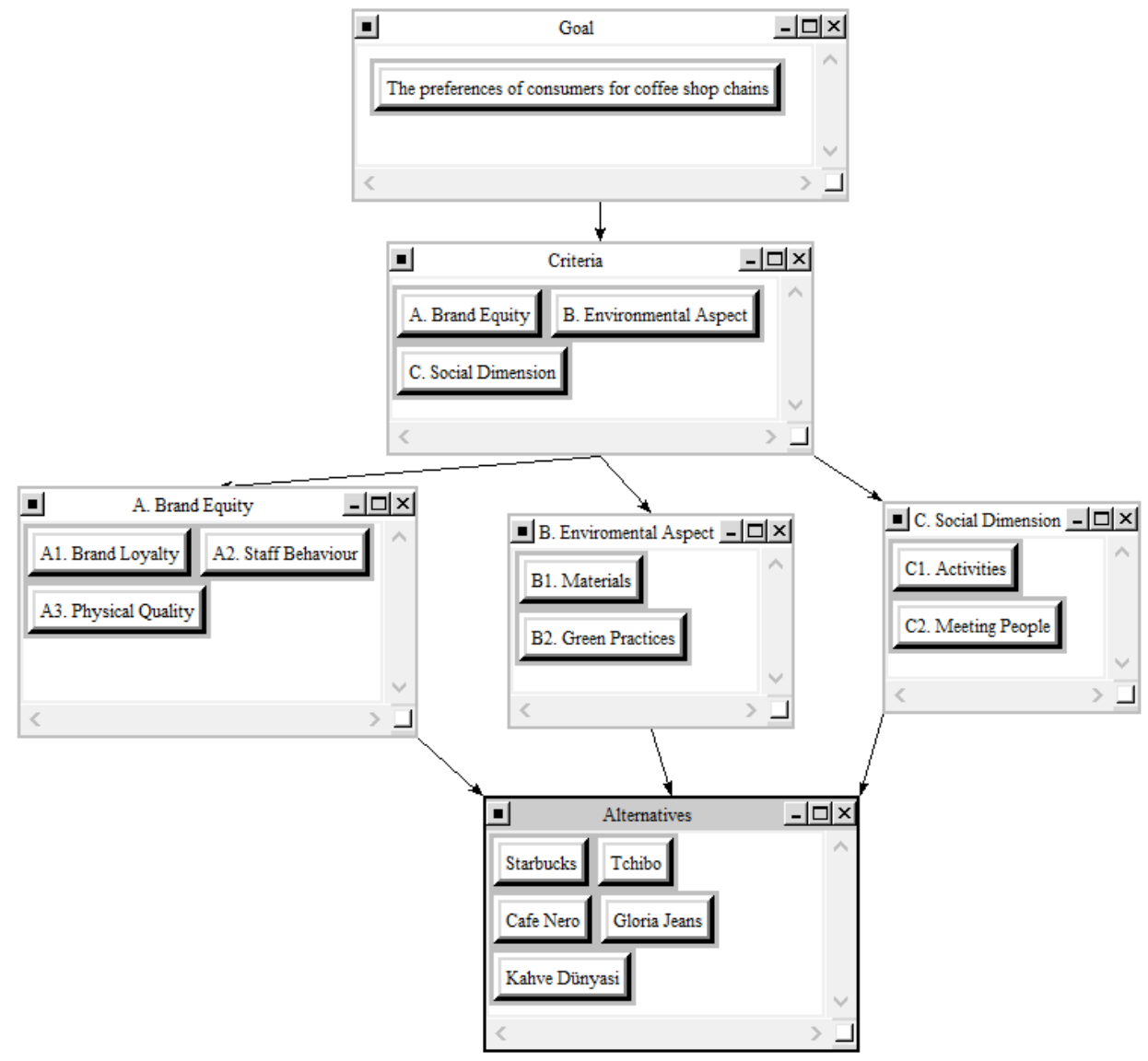

Figure1: Decision Model in Super decisions Software

\section{Data/Model Analysis}

In accordance with iterative steps of AHP, after constructing the hierarchy, the authors pose the customers of coffee shop chains in Turkey pairwise comparison questions to assess the relative priorities of evaluation criteria and then have the respondents rate the coffee chains. Quota sampling is used and 30 university students are taken as the target group of the survey.

Table 1 exhibits the relative importance of criteria and sub-criteria. The relative preference for the coffee shop chains are given at Table 2 . 
ISAHP Article: A Style Guide for Paper Proposals To Be Submitted to the International Symposium on the Analytic Hierarchy Process 2016, London, U.K.

\begin{tabular}{|c|c|c|c|}
\hline Criteria & Weight & Sub-Criteria & Weight \\
\hline \multirow{3}{*}{ Brand Equity } & \multirow{3}{*}{$33.70 \%$} & Brand Loyalty & $7.75 \%$ \\
\cline { 3 - 4 } & & Physical Quality & $13.33 \%$ \\
\cline { 3 - 4 } & \multirow{2}{*}{$39.85 \%$} & Staff Behavior & $12.60 \%$ \\
\hline Environmental Aspect & Green Practice & $16.02 \%$ \\
\cline { 3 - 4 } & \multirow{2}{*}{$26.44 \%$} & Materials & $23.83 \%$ \\
\hline Social Dimension & & Activities & $9.97 \%$ \\
\cline { 3 - 4 } & & Meeting P. & $16.46 \%$ \\
\hline
\end{tabular}

Table 1: Importance of Criteria and Importance of Sub-Criteria

\begin{tabular}{cc}
\hline \hline Coffee Shops Chains & Global Score \\
\hline \hline Starbucks & 0.6611 \\
Café Nero & 0.6548 \\
Gloria Jeans & 0.6390 \\
Tchibo & 0.6216 \\
Kahve Dünyası & 0.5800 \\
\hline
\end{tabular}

Table 2: The Preferences for Coffee Shop Chains

\section{Conclusion}

This study aims to reveal the preferences of the university students for coffee shop chains. The evaluation factors are identified and prioritized. According to the results, environmental aspects are found more important than other main criteria. Also, the most preferred evaluation criterion for the participants of the survey is materials $(23.83 \%)$ followed by green practices $(16.02 \%)$, physical quality $(13.33 \%)$, and staff behavior $(12.60 \%)$; on the other hand the least preferred evaluation factor for the participants of survey is brand loyalty $(7.75 \%)$. The most preferred coffee shop chain is found as Starbucks (.6611 out of 1$)$ followed by Café Nero ( 0.6548 out of 1$)$.

The survey results can be generalized by expanding the participant group and interacted with other customers of the coffee shop chains. Results of different groups can be compared and discussed. Another research avenue can be exploring the dependencies and feedback among evaluation factors and utilizing ANP for the problem on hand.

\section{Key References}

Bhumiratana, N., Adhikari, K. and Chambers, E. (2014). The development of an emotion lexicon for the coffee drinking experience. Food Research International, 61, 83-92.

Han, S.H., Nguyen, B. and Lee, T.J. (2015). Consumer-based chain restaurant brand equity, brand reputation, and brand trust. International Journal of Hospitality Management, 50, 84-93.

Jeong, E., Jang, S., Day, J. and Ha, S. (2014). The impact of eco-friendly practices on green image and customer attitudes: An investigation in cafe setting. International Journal of Hospitality Management, 40, 10-20.

Nam, J., Ekinci, Y. and Whyatt, G. (2011). Brand Equity, Brand Loyalty and Consumer Satisfaction. Annals of Tourism Research, 36(3), 1009-1030.

Tumanan, M.A.R. and Lansangan, J.R.G. (2012). More than just a cuppa coffee: A multidimensional approach towards analyzing the factors that define place attachment. International Journal of Hospitality Management, 31, 529-534. 
ISAHP Article: A Style Guide for Paper Proposals To Be Submitted to the International Symposium on the Analytic Hierarchy Process 2016, London, U.K.

Vanharanta, H., Kantola, J. and Seikola, S. (2015). Customers' conscious experience in a coffee shop. Procedia Manufacturing, 3, 618-625. 